\title{
Characteristics and Outcomes in Patients with Venous Thromboembolism Taking Concomitant Anti-Platelet Agents and Anticoagulants in the AMPLIFY Trial
}

\author{
Alexander T. Cohen ${ }^{1}$ Giancarlo Agnelli ${ }^{2}$ Harry R. Buller ${ }^{3} \quad$ Alexander Gallus $^{4}$ Gary E. Raskob ${ }^{5}$ \\ Paul Sanders ${ }^{6}$ John Thompson ${ }^{7}$ Jeffrey I. Weitz ${ }^{8}$
}

${ }^{1}$ Department of Haematology, Guy's and St Thomas' Hospitals, King's College London, London, United Kingdom

2 Internal, Vascular and Emergency Medicine, University of Perugia, Perugia, Italy

${ }^{3}$ Department of Vascular Medicine, Academic Medical Center, Universiteit van Amsterdam, Amsterdam, The Netherlands

${ }^{4}$ Department of Haematology, Flinders Medical Centre, Flinders University, Adelaide, Australia

${ }^{5}$ Hudson College of Public Health, University of Oklahoma Health Sciences Center, Oklahoma City, University of Oklahoma, Oklahoma, United States

6 Pfizer Ltd, Walton Oaks, Walton on the Hill, Tadworth, Surrey, United Kingdom

7 Pfizer Inc, Groton, Connecticut, United States

8 McMaster University and the Thrombosis and Atherosclerosis

Research Institute, Hamilton, Ontario, Canada

Address for correspondence Alexander T. Cohen, MD, Thrombosis and Thrombophilia Unit, Department of Haematology, Guy's and St Thomas' Hospitals NHS Foundation Trust, Westminster Bridge Road, London SE1 7EH, United Kingdom (e-mail: alexander.cohen@kcl.ac.uk).

Thromb Haemost 2019;119:461-466.

\section{Abstract}

\section{Keywords}

- anti-platelet agents

- venous thrombosis

- clinical trials: oral anticoagulants

- deep vein thrombosis

- pulmonary embolism
The double-blind, randomized, AMPLIFY trial compared 6 months' treatment with apixaban (10 mg twice daily for 7 days and $5 \mathrm{mg}$ twice daily thereafter) versus conventional treatment (subcutaneous enoxaparin [ $1 \mathrm{mg} / \mathrm{kg}$ twice daily for $\geq 5$ days] overlapped and followed by warfarin [international normalized ratio $=2.0-3.0$ ]) in patients with acute venous thromboembolism (VTE). This post hoc analysis of AMPLIFY compared outcomes among those taking or not taking concomitant anti-platelet therapy. The primary efficacy outcome was recurrent VTE or VTE-related death; the principal safety outcome was major bleeding. Of 5,365 (apixaban, $n=2,676$; enoxaparin/warfarin, $n=2,689$ ) randomized patients, 813 (apixaban, $n=402$ [15\%]; enoxaparin/warfarin, $n=411$ [15\%]) took concomitant anti-platelet therapy, of which $92 \%$ consisted of low-dose aspirin. Rates of VTE or VTE-related death were similar whether or not anti-platelet agents were taken (apixaban: 3.6 and 2.0\%; enoxaparin/warfarin: 3.0 and 2.6\%; anti-platelet use: relative risk [RR], 1.23; 95\% confidence interval [Cl], 0.58-2.62; no anti-platelet use: $R R, 0.77 ; 95 \% \mathrm{Cl}$, $0.52-1.13$ ); interaction $p$-value $=0.299$. Major bleeding rates were threefold higher in those taking versus those not taking anti-platelet agents (apixaban: 1.2 and $0.4 \%$; enoxaparin/warfarin: 4.1 and 1.4\%; anti-platelet use: RR, 0.30 ; $95 \% \mathrm{Cl}, 0.11-0.81$; no anti-platelet use: $\mathrm{RR}, 0.31 ; 95 \% \mathrm{Cl}, 0.15-0.63)$; interaction $p$-value $=0.924$. Concomitant anti-platelet therapy produced a proportionally similar increase in major bleeding in patients randomized to apixaban or conventional therapy, but there were fewer major bleeds with apixaban. Therefore, the overall safety of apixaban over conventional therapy was maintained in patients receiving anti-platelet therapy. Clinicaltrials.gov: NCT00643201. received

February 15, 2018

accepted after revision

November 21, 2018
DOI https://doi.org/

$10.1055 / \mathrm{s}-0038-1676983$

ISSN 0340-6245. (c) 2019 Georg Thieme Verlag KG Stuttgart · New York
License terms

() (1) $\Theta \circledast$ 


\section{Introduction}

Apixaban is an oral factor Xa inhibitor that is indicated for stroke prevention in non-valvular atrial fibrillation and for treatment and prevention of venous thromboembolism (VTE). When compared with warfarin, apixaban was at least as effective and was associated with significantly less bleeding. ${ }^{1}$ With similar efficacy, significantly less bleeding and greater convenience than warfarin for VTE treatment, apixaban is an attractive alternative.

The risk factors for venous and arterial thrombosis overlap. ${ }^{2}$ Furthermore, atherosclerosis is a risk factor for unprovoked VTE; ${ }^{3}$ patients with unprovoked VTE are at increased risk of future arterial cardiovascular events. ${ }^{4}$ Consequently, approximately $10 \%$ of patients with VTE receive concomitant anti-platelet therapy, often with aspirin. ${ }^{5,6}$ Such patients tend to be older and to have more co-morbidities than those not receiving anti-platelet agents. ${ }^{7,8}$ Some studies have shown that administration of anti-platelet drugs in conjunction with vitamin K antagonists such as warfarin is associated with increased bleeding. ${ }^{9,10}$ However, data on bleeding with concomitant anticoagulant and anti-platelet therapy in patients with VTE are scarce. Furthermore, it is unknown how the benefit-to-risk profile of warfarin compares with that of apixaban in patients with VTE who require concomitant anti-platelet therapy. To address this question, this analysis of the AMPLIFY trial compared the patient characteristics and the efficacy and safety of apixaban and enoxaparin/warfarin in patients taking concomitant anti-platelet therapy with those in patients not taking such therapy.

\section{Materials and Methods}

\section{Study Design}

The AMPLIFY trial (NCT00643201) was a randomized, activecontrolled, parallel-group, double-blind, non-inferiority trial conducted at 358 centres in 28 countries. The study design and methods have been previously reported in detail. ${ }^{1}$ The study was conducted in accordance with the Declaration of Helsinki and Good Clinical Practice guidelines. The study protocol was approved by the Institutional Review Board and ethics committee of each participating study centre and all patients provided written informed consent.

\section{Patients}

Eligible patients were at least 18 years of age and had objectively confirmed symptomatic proximal deep vein thrombosis (DVT), pulmonary embolism (PE) or both. ${ }^{1}$ Patients who received anti-platelet therapy at any time during the clinical trial were identified, and rates for the adjudicated primary safety and efficacy endpoints in these patients were compared with those in patients not taking anti-platelet drugs.

The trial excluded patients receiving dual anti-platelet therapy or aspirin at daily doses greater than $165 \mathrm{mg}$. Other major exclusion criteria included active bleeding or a high risk of bleeding; potent inhibitors of cytochrome P-450 3A4; treatment longer than 48 hours with low-molecular-weight heparin, unfractionated heparin or fondaparinux prior to enrolment; treatment of the index VTE with thrombectomy, vena cava filter or thrombolytic therapy; and creatinine clearance of $<25 \mathrm{~mL} / \mathrm{min}$, haemoglobin concentration of $<90 \mathrm{~g} / \mathrm{L}$ or platelet count of $<100 \times 10^{9} / \mathrm{L}$. Patients with a life expectancy of less than 6 months were also excluded.

\section{Randomization and Masking}

Randomization was performed with the use of an interactive voice-response system and was stratified according to the qualifying diagnosis of either symptomatic proximal DVT or symptomatic PE (with or without DVT). Eligible patients were randomized 1:1 to a 6-month course of apixaban (10 mg twice daily for 7 days followed by $5 \mathrm{mg}$ twice daily thereafter) or to conventional therapy (enoxaparin $1 \mathrm{mg} / \mathrm{kg}$ twice daily for at least 5 days overlapped with warfarin dose-adjusted to achieve an international normalized ratio [INR] of 2.0-3.0).

The study used blinded INR monitoring with a point-of-care device that generated an encrypted code for INR results. Investigators reported the code to the interactive voiceresponse system and received either an actual INR value (for patients assigned to warfarin) or a sham INR value (for patients receiving apixaban). Evaluation of the INR was required at least monthly, or more frequently if clinically indicated.

\section{Procedures}

Patients were assigned to receive apixaban tablets plus placebo enoxaparin injections and placebo warfarin tablets or conventional therapy with enoxaparin injections and warfarin tablets plus placebo apixaban tablets. Patients assigned to the apixaban group received $10 \mathrm{mg}$ of apixaban twice daily for the first 7 days, followed by $5 \mathrm{mg}$ twice daily for 6 months. Patients assigned to the conventional therapy group received enoxaparin at a dose of $1 \mathrm{mg} / \mathrm{kg}$ of body weight every 12 hours for at least 5 days; warfarin began concomitantly and continued for 6 months. The warfarin dose was adjusted to maintain an INR of between 2.0 and 3.0.

Patients underwent assessment, either in the clinic or by telephone, at weeks 2, 4, 8, 12, 16, 20 and 24 (6 months) after randomization and 30 days after the end of the intended treatment period. Patients were instructed to report to the study centre if they had symptoms suggestive of recurrent VTE or bleeding. Pre-specified objective testing was required for patients in whom an outcome event was suspected.

\section{Study Outcomes}

The primary efficacy outcome was objectively confirmed symptomatic VTE or VTE-related death. The intention-totreat efficacy analysis included all randomized patients with a non-missing primary outcome. The principal safety outcome was major bleeding up to 2 days after stopping study drug in all randomized patients who received at least one dose of study drug. Major bleeding was defined as overt bleeding associated with a decrease in haemoglobin of $\geq 20 \mathrm{~g} / \mathrm{L}$, transfusion of at least two units of packed red blood cells, bleeding that occurred in a critical site (intracranial, intra-spinal, intraocular, pericardial, intra-articular, intramuscular with compartment syndrome or retroperitoneal) or 
bleeding that was fatal. Clinically relevant non-major bleeding was defined as overt bleeding that did not meet the criteria for major bleeding but was associated with medical intervention, unscheduled contact with a physician, interruption or discontinuation of study drug or discomfort or impairment of activities of daily living. All efficacy and safety outcomes were adjudicated by an independent committee blinded to treatment assignment.

\section{Statistical Analyses}

The current analysis is a sub-group analysis of the AMPLIFY population; however, it was not pre-specified prior to the completion of the study. Efficacy analysis included data from patients in the intention-to-treat population for whom outcome status at 6 months was documented. Safety sub-group analyses included data obtained from all randomized patients who received at least one dose of study drug during the treatment period, defined as the time from administration of the first dose until 48 hours after the last dose was given. The 95\% confidence interval (CI) for the relative risk (RR) was calculated using the Mantel-Haenszel method, stratified by the qualifying diagnosis (DVTor PE). Wald's chi-square test was used to test whether treatment had statistically significantly different effects on the rates of endpoints across sub-groups based on a logistic model that included terms for treatment, sub-population and treatment by sub-population interactions.

\section{Results}

\section{Study Population}

Overall, the AMPLIFY study demonstrated that apixaban was non-inferior to conventional therapy for the primary efficacy outcome with rates of recurrent symptomatic VTE or VTErelated death of 2.3 and $2.7 \%$, respectively (RR, $0.84 ; 95 \% \mathrm{CI}$, $0.60-1.18 ; p<0.001$ for non-inferiority), but was associated with significantly less major bleeding ( 0.6 and $1.8 \%$, respectively; RR, 0.31 ; $95 \% \mathrm{CI}, 0.17-0.55 ; p<0.001$ for superiority). ${ }^{1}$

Of the 2,676 patients randomized to apixaban and the 2,689 randomized to conventional therapy between 27 August 2008 (first subject first visit) and 12 March 2013 (last subject last visit), $402(15 \%)$ and $411(15 \%)$, respectively (-Supplementary Table S1, available in the online version), received concomitant anti-platelet therapy, consisting of low-dose aspirin in $92 \%$ of cases. Patients receiving concomitant anti-platelet agents were older, more likely to be male and had higher frequencies of moderate renal impairment, cardiovascular risk factors and cardiovascular disease than those not receiving such therapy (-Table 1). The baseline characteristics of the patients receiving anti-platelet agents were similar in the two treatment groups.

In the apixaban and conventional therapy groups, antiplatelet agents were used for a median (interquartile range) of 162.5 (3-169) days and 155.0 (4-169) days, respectively; the median anticoagulation use was 168 days for both treatment groups.

\section{Efficacy and Safety Outcomes}

The rates of recurrent VTE or VTE-related death in the combined treatment groups for those taking or not taking anti-platelet therapy were 3.3 and $2.3 \%$, respectively. The rates of major bleeding in the combined treatment groups for those taking or not taking anti-platelet therapy were 2.7 and $0.9 \%$, respectively.

As outlined in - Table $\mathbf{2}$ and - Fig. 1, rates of VTE or VTErelated death were similar in those taking or not taking concomitant anti-platelet drugs in both the apixaban group (3.6 and 2.0\%, respectively) and the warfarin group (3.0 and $2.6 \%$, respectively). The rates of recurrent VTE or VTE-related death with apixaban and conventional therapy were similar both in those taking anti-platelet agents ( RR, $1.23 ; 95 \% \mathrm{CI}, 0.58$ 2.62) and in those not taking anti-platelet drugs (RR, 0.77; 95\% $\mathrm{CI}, 0.52-1.13)$. In patients taking concomitant anti-platelet therapy, major bleeds occurred in 5 patients in the apixaban group and in 17 patients in the conventional treatment group (RR, 0.30; 95\% CI, 0.11-0.81). In the apixaban group, the rate of major bleeding in those taking concomitant anti-platelet drugs was threefold higher than in those not taking these agents (1.2 and $0.4 \%$, respectively). Likewise, in the conventional treatment group, the rate of major bleeding in patients taking concomitant anti-platelet drugs was 2.9-fold higher than in those not taking these agents ( 4.1 and $1.4 \%$, respectively). In patients who received anti-platelet therapy, clinically relevant non-major bleeds occurred in 18 patients in the apixaban group and in 54 patients in the conventional treatment group (RR, $0.35 ; 95 \% \mathrm{CI}$, 0.21-0.58) (-Table 2 and - Fig. 1).

Details of the sites of major bleeding events and the comparison of the characteristics in those who did and did not receive concomitant anti-platelet therapy are shown in - Table 3.

\section{Discussion}

This post hoc sub-group analysis, which included over 800 patients with VTE taking anti-platelet therapy, reveals that apixaban was not less effective than conventional therapy in patients taking concomitant anti-platelet therapy and is associated with less bleeding. These results are consistent with the overall findings of the AMPLIFY trial.

In keeping with previous reports, ${ }^{8}$ the overall rates of major and clinically relevant non-major bleeding were higher in patients taking concomitant anti-platelet therapy than in those not taking these agents regardless of whether they were on apixaban or warfarin. However, the relative reduction in bleeding rates with apixaban compared with warfarin was maintained in this sub-group of patients. Therefore, in patients with VTE requiring concomitant anti-platelet therapy, apixaban may be a safer choice than warfarin. Since aspirin was the anti-platelet agent used in $90 \%$ or more of patients who received anti-platelet agents in the AMPLIFY trial, our findings may not apply to patients taking dual anti-platelet therapy, clopidogrel, or newer P2Y12 inhibitors such as ticagrelor and prasugrel.

The limitations of this analysis include the fact that it is a post hoc analysis and the results are therefore only hypothesis generating. Accordingly, the analysis was also limited in power for efficacy outcomes and interactions. Additionally, the 25th percentile of median duration of anti-platelet use was within the first week after randomization, which could 
Table 1 Baseline characteristics of trial participants

\begin{tabular}{|c|c|c|c|c|}
\hline \multirow[b]{2}{*}{ Treatment } & \multicolumn{2}{|c|}{ Anti-platelet use } & \multicolumn{2}{|c|}{ No anti-platelet use } \\
\hline & $\begin{array}{l}\text { Apixaban } \\
(n=402)\end{array}$ & $\begin{array}{l}\text { Enoxaparin/warfarin } \\
(n=411)\end{array}$ & $\begin{array}{l}\text { Apixaban } \\
(n=2289)\end{array}$ & $\begin{array}{l}\text { Enoxaparin/warfarin } \\
(n=2,293)\end{array}$ \\
\hline Age $(y)$ & $64.9(13.9)$ & $63.7(13.9)$ & $55.9(16.0)$ & $55.4(16.1)$ \\
\hline$<65$ & $179(44.5 \%)$ & $197(47.9 \%)$ & $1,550(67.7 \%)$ & $1,565(68.3 \%)$ \\
\hline $65-<75$ & $113(28.1 \%)$ & $118(28.7 \%)$ & $447(19.5 \%)$ & $452(19.7 \%)$ \\
\hline$\geq 75$ & $110(27.4 \%)$ & $96(23.4 \%)$ & $292(12.8 \%)$ & $276(12.0 \%)$ \\
\hline Male & $244(60.7 \%)$ & $249(60.6 \%)$ & $1,325(57.9 \%)$ & $1,349(58.8 \%)$ \\
\hline Weight (kg) & $87.0(21.8)$ & $86.9(20.1)$ & $84.1(19.3)$ & $84.2(19.7)$ \\
\hline \multicolumn{5}{|l|}{ Creatinine clearance $(\mathrm{mL} / \mathrm{min})$} \\
\hline$>80$ & $181(45.0 \%)$ & $219(53.3 \%)$ & $1,540(67.3 \%)$ & $1,538(67.1 \%)$ \\
\hline$>50-\leq 80$ & $122(30.3 \%)$ & $101(24.6 \%)$ & $427(18.7 \%)$ & $443(19.3 \%)$ \\
\hline$>30-\leq 50$ & $52(12.9 \%)$ & $43(10.5 \%)$ & $109(4.8 \%)$ & $105(4.6 \%)$ \\
\hline$\leq 30$ & $6(1.5 \%)$ & $5(1.2 \%)$ & $8(0.3 \%)$ & $10(0.4 \%)$ \\
\hline Not reported & $41(10.2 \%)$ & $43(10.5 \%)$ & $205(9.0 \%)$ & $197(8.6 \%)$ \\
\hline \multicolumn{5}{|l|}{ Index VTE } \\
\hline Provoked & $45(11.2 \%)$ & $33(8.0 \%)$ & $227(9.9 \%)$ & $239(10.4 \%)$ \\
\hline Unprovoked & $356(88.6 \%)$ & $378(92.0 \%)$ & $2,060(90.0 \%)$ & $2,051(89.4 \%)$ \\
\hline Not reported & $1(0.2 \%)$ & 0 & $2(<0.1 \%)$ & $3(0.1 \%)$ \\
\hline \multicolumn{5}{|l|}{ Risk factors for recurrent VTE } \\
\hline Active cancer & $9(2.2 \%)$ & $17(4.1 \%)$ & $57(2.5 \%)$ & $60(2.6 \%)$ \\
\hline Persistent or permanent immobility & $44(10.9 \%)$ & $21(5.1 \%)$ & $143(6.2 \%)$ & $139(6.1 \%)$ \\
\hline Previous PE or proximal DVT & $72(17.9 \%)$ & $68(16.5 \%)$ & $391(17.1 \%)$ & $341(14.9 \%)$ \\
\hline History of pro-thrombotic genotype & $4(1.0 \%)$ & $3(0.7 \%)$ & $70(3.1 \%)$ & $56(2.4 \%)$ \\
\hline Hypercholesterolaemia & $188(46.8 \%)$ & $190(46.2 \%)$ & $488(21.3 \%)$ & $437(19.1 \%)$ \\
\hline Hypertension & $269(66.9 \%)$ & $277(67.4 \%)$ & $881(38.5 \%)$ & $855(37.3 \%)$ \\
\hline Subjects using an anti-platelet agent & $402(100 \%)$ & $411(100 \%)$ & 0 & 0 \\
\hline Acetylsalicylic acid & $378(94.0 \%)$ & $366(89.1 \%)$ & 0 & 0 \\
\hline Clopidogrel & $26(6.5 \%)$ & $40(9.7 \%)$ & 0 & 0 \\
\hline
\end{tabular}

Abbreviations: DVT, deep vein thrombosis; PE, pulmonary embolism; SD, standard deviation; VTE, venous thromboembolism. Note: Data are number (\%) or mean (SD).

Table 2 Analysis of major bleeding events, clinically relevant non-major bleeding events and VTE recurrence by anti-platelet use

\begin{tabular}{|c|c|c|c|c|}
\hline & Apixaban $(n=2,676)$ & Enoxaparin/warfarin $(n=2,689)$ & $\mathrm{RR}(95 \% \mathrm{Cl})$ & $\operatorname{ARR}(95 \% \mathrm{Cl})$ \\
\hline \multicolumn{5}{|c|}{ Major bleeding by anti-platelet use } \\
\hline $\begin{array}{l}\text { Anti-platelet }-n / N \\
\text { Event rate }(95 \% \mathrm{Cl})\end{array}$ & $\begin{array}{l}5 / 402 \\
1.2 \%(0.16 \%, 2.3 \%)\end{array}$ & $\begin{array}{l}17 / 411 \\
4.1 \%(2.2 \%, 6.1 \%)\end{array}$ & $\begin{array}{l}0.30 \\
(0.11,0.81)\end{array}$ & $\begin{array}{l}-2.9 \% \\
(-5.8 \%, 0 \%)\end{array}$ \\
\hline $\begin{array}{l}\text { No anti-platelet }-n / N \\
\text { Event rate }(95 \% \mathrm{Cl})\end{array}$ & $\begin{array}{l}10 / 2,274 \\
0.44 \%(0.2 \%, 0.7 \%)\end{array}$ & $\begin{array}{l}32 / 2,278 \\
1.40 \%(0.9 \%, 1.9 \%)\end{array}$ & $\begin{array}{l}0.31 \\
(0.15,0.63)\end{array}$ & $\begin{array}{l}-1.0 \% \\
(-1.7 \%,-0.2 \%)\end{array}$ \\
\hline \multicolumn{5}{|c|}{ Clinically relevant non-major bleeding by anti-platelet use } \\
\hline & Apixaban $(n=2,676)$ & Enoxaparin/warfarin $(n=2,689)$ & $\mathrm{RR}(95 \% \mathrm{Cl})$ & $\operatorname{ARR}(95 \% \mathrm{Cl})$ \\
\hline $\begin{array}{l}\text { Anti-platelet }-n / N \\
\text { Event rate }(95 \% \mathrm{Cl})\end{array}$ & $\begin{array}{l}18 / 402 \\
4.5 \%(2.5 \%, 6.5 \%)\end{array}$ & $\begin{array}{l}54 / 411 \\
13.1 \%(9.9 \%, 16.4 \%)\end{array}$ & $\begin{array}{l}0.35 \\
(0.21,0.58)\end{array}$ & $\begin{array}{l}-8.7 \% \\
(-13.7 \%,-3.2 \%)\end{array}$ \\
\hline $\begin{array}{l}\text { No anti-platelet }-n / N \\
\text { Event rate }(95 \% \mathrm{Cl})\end{array}$ & $\begin{array}{l}85 / 2,274 \\
3.7 \%(3.0 \%, 4.5 \%)\end{array}$ & $\begin{array}{l}161 / 2,278 \\
7.1 \%(6.0 \%, 8.1 \%)\end{array}$ & $\begin{array}{l}0.53 \\
(0.41,0.68)\end{array}$ & $\begin{array}{l}-3.3 \% \\
(-5.1 \%,-1.6 \%)\end{array}$ \\
\hline \multicolumn{5}{|c|}{ VTE and VTE-related death by anti-platelet use } \\
\hline & Apixaban $(n=2,691)$ & Enoxaparin/warfarin $(n=2,704)$ & $\mathrm{RR}(95 \% \mathrm{CI})$ & $\operatorname{ARR}(95 \% \mathrm{Cl})$ \\
\hline $\begin{array}{l}\text { Anti-platelet }-n / N \\
\text { Event rate }(95 \% \mathrm{Cl})\end{array}$ & $\begin{array}{l}14 / 390 \\
3.6 \%(1.7 \%, 5.4 \%)\end{array}$ & $\begin{array}{l}12 / 403 \\
2.98 \%(0.13 \%, 4.6 \%)\end{array}$ & $\begin{array}{l}1.23 \\
(0.58,2.62)\end{array}$ & $\begin{array}{l}0.6 \% \\
(-2.6 \%, 3.9 \%)\end{array}$ \\
\hline $\begin{array}{l}\text { No anti-platelet }-n / N \\
\text { Event rate }(95 \% \mathrm{Cl})\end{array}$ & $\begin{array}{l}45 / 2,219 \\
2.0 \%(1.4 \%, 2.6 \%)\end{array}$ & $\begin{array}{l}59 / 2,232 \\
2.6 \%(2.0 \%, 3.3 \%)\end{array}$ & $\begin{array}{l}0.77 \\
(0.52,1.13)\end{array}$ & $\begin{array}{l}-0.6 \% \\
(-1.8 \%, 0.5 \%)\end{array}$ \\
\hline
\end{tabular}

Abbreviations: ARR, absolute risk reduction; $\mathrm{Cl}$, confidence interval; RR, relative risk; VTE, venous thromboembolism. 


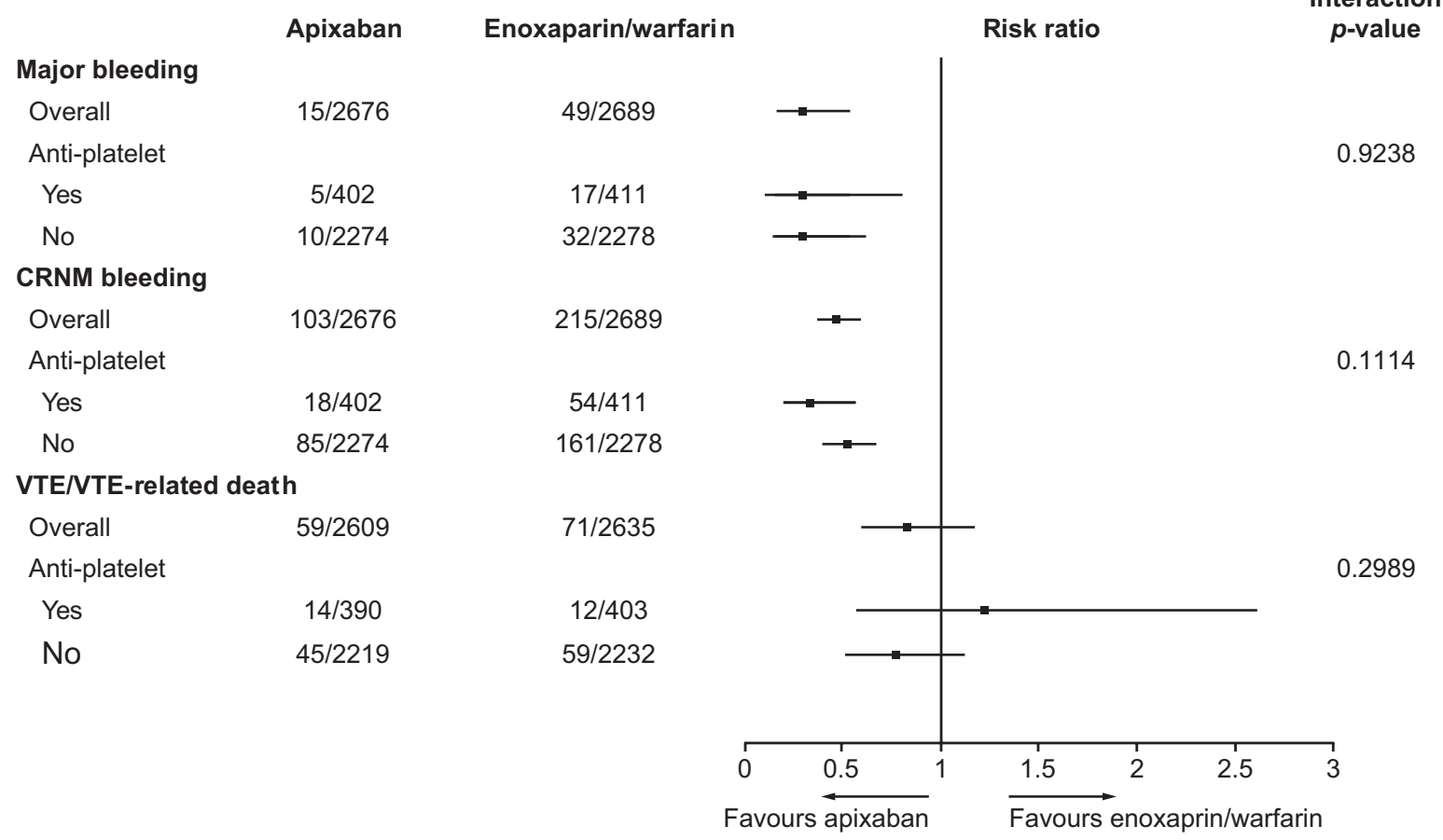

Fig. 1 Major bleeding, clinically relevant non-major bleeding and VTE recurrences in patients receiving and not receiving anti-platelet therapy. CRNM, clinically relevant non-major; VTE, venous thromboembolism.

Table 3 Summary of major bleeding events by site of bleeding or characteristic by anti-platelet use

\begin{tabular}{|c|c|c|c|c|c|c|}
\hline \multirow[t]{2}{*}{ Major bleeding type } & \multicolumn{3}{|c|}{ Anti-platelet use } & \multicolumn{3}{|c|}{ No anti-platelet use } \\
\hline & $\begin{array}{l}\text { Apixaban } \\
(n=402)\end{array}$ & $\begin{array}{l}\text { Enoxaparin/warfarin } \\
(n=411)\end{array}$ & $\begin{array}{l}\text { Total } \\
(n=813)\end{array}$ & $\begin{array}{l}\text { Apixaban } \\
(n=2,274)\end{array}$ & $\begin{array}{l}\text { Enoxaparin/warfarin } \\
(n=2,278)\end{array}$ & $\begin{array}{l}\text { Total } \\
(N=4,552)\end{array}$ \\
\hline Major bleeding, $n(\%)$ & $5(1.2)$ & $17(4.1)$ & $22(2.7)$ & $10(0.4)$ & $32(1.4)$ & $42(0.9)$ \\
\hline $\begin{array}{l}\text { Fatal bleeding } \\
\text { (by primary site of bleeding) }\end{array}$ & & & & 1 & 2 & 3 \\
\hline Gastrointestinal & & & & 0 & 1 & 1 \\
\hline Intramuscular & & & & 0 & 1 & 1 \\
\hline Rectal & & & & 1 & 0 & 1 \\
\hline \multicolumn{7}{|l|}{ Critical site $^{a}$} \\
\hline Intracranial & 2 & 1 & 3 & 1 & 5 & 6 \\
\hline Retroperitoneal & 1 & 1 & 2 & 0 & 2 & 2 \\
\hline Intraocular & 0 & 1 & 1 & 0 & 1 & 1 \\
\hline Intra-articular & & & & 0 & 2 & 2 \\
\hline Other critical organ & & & & 0 & 1 & 1 \\
\hline \multicolumn{7}{|l|}{ Other site $^{a}$} \\
\hline Gastrointestinal & 1 & 7 & 8 & 5 & 10 & 15 \\
\hline Intramuscular & 0 & 3 & 3 & 0 & 2 & 2 \\
\hline Nasal & & & & 1 & 1 & 2 \\
\hline Other & & & & 0 & 1 & 1 \\
\hline Rectal & 1 & 1 & 2 & & & \\
\hline Skin & 0 & 3 & 3 & 1 & 3 & 4 \\
\hline Urogenital & & & & 1 & 3 & 4 \\
\hline $\begin{array}{l}\text { Fall in haemoglobin } \geq 20 \mathrm{~g} / \mathrm{L} \\
\text { or transfusions } \geq 2 \text { units }\end{array}$ & 2 & 15 & 17 & 8 & 24 & 32 \\
\hline
\end{tabular}

Note: The denominator to calculate each percentage is the total number of treated subjects in each treatment group for the specified sub-group. If a subject has more than one bleeding with the same bleeding type, only the earliest one is counted.

${ }^{a}$ Bleeding into a critical site qualifies as a major bleed with or without a $>20 \mathrm{~g} / \mathrm{L}$ drop in haemoglobin or transfusion. Some subjects with a major bleed due to bleeding into a critical site also had a $>20 \mathrm{~g} / \mathrm{L}$ drop in haemoglobin or transfusion. All subjects with a major bleed at an 'other site' also had a $>20 \mathrm{~g} / \mathrm{L} \mathrm{drop} \mathrm{in}$ haemoglobin or transfusion to qualify as a major bleed. 
potentially bias the findings reported here, although the median durations were similar for both the apixaban and conventional therapy groups.

In clinical practice, and as seen in the AMPLIFY study, a significant proportion of patients with VTE have a history of cardiovascular events, an indication for which antiplatelet therapy often is prescribed. ${ }^{1,5}$ The results of this study suggest that apixaban may not only be a more convenient option than warfarin for VTE treatment but also a safer alternative, even when concomitant antiplatelet therapy is prescribed. Additional randomized and larger observational studies are needed to confirm these findings.

\section{What is known about this topic?}

- There is increasing evidence of a link between venous and arterial thrombosis because of overlapping risk factors. Consequently, many patients with venous thromboembolism (VTE) require concomitant antiplatelet therapy, often with aspirin.

- Co-administration of anti-platelet drugs with vitamin $\mathrm{K}$ antagonists such as warfarin has been shown to increase bleeding.

- How the benefit-risk profile of warfarin compares with that of apixaban in patients with VTE requiring concomitant anti-platelet therapy is unknown.

\section{What does this paper add?}

- This analysis of the AMPLIFY trial affirms the overall benefit-risk profile of apixaban in patients with VTE with or without concomitant single anti-platelet therapy.

- While rates of recurrent VTE were similar with apixaban and conventional therapy in AMPLIFY, the rates of major and clinically relevant non-major bleeds were each significantly lower in patients treated with apixaban compared with the conventional therapy, regardless of whether patients did or did not receive concomitant anti-platelet therapy.

- These results suggest that apixaban is not only more convenient than warfarin but is also associated with significantly less bleeding in patients with VTE who do or do not require concomitant anti-platelet therapy.

\section{Authors' Contributions}

A.T.C., G.A., H.R.B., A.G., G.E.R. and J.I.W. designed the study, and analysed and interpreted the data. P.S. and J.T. analysed and interpreted the data. All authors had full access to the data. A.T.C. prepared the first draft of the manuscript, and all authors revised it critically for important intellectual content. All authors gave their consent to the final version of the manuscript.

\section{Funding}

Pfizer and Bristol-Myers Squibb sponsored the AMPLIFY study and the analysis reported here. The steering committee, consisting of academic authors and authors who are employees of Pfizer, had final responsibility for the study design, oversight and data verification and analyses. The sponsors collected and maintained the data. All authors had full access to the data at all times and interpreted the data.

\section{Conflict of Interest}

A.T.C., G.A., H.R.B., A.G., G.E.R. and J.I.W. received honoraria as Steering Committee members of the AMPLIFY trial and were paid consultants to Bristol-Myers Squibb and Pfizer in connection with the development of this manuscript. P.S. is an employee of Pfizer, Inc. J.T. was an employee of Pfizer, Inc. at the time of this work.

\section{Acknowledgements}

The authors would like to thank the patients who participated in the AMPLIFY trial and the study nurses for their work in enrolling these patients. The authors would also like to acknowledge the substantial contributions of Dr. Madelyn Curto to the analysis and interpretation of the study results. Editorial support, consisting of manuscript formatting with no contribution made to content, was provided by Hannah Lederman, MPhil, at Caudex and funded by Bristol-Myers Squibb and Pfizer, Inc.

\section{References}

1 Agnelli G, Buller HR, Cohen A, et al; AMPLIFY Investigators. Oral apixaban for the treatment of acute venous thromboembolism. $\mathrm{N}$ Engl J Med 2013;369(09):799-808

2 Prandoni P. Venous and arterial thrombosis: two aspects of the same disease? Clin Epidemiol 2009;1:1-6

3 Prandoni P, Bilora F, Marchiori A, et al. An association between atherosclerosis and venous thrombosis. N Engl J Med 2003;348 (15):1435-1441

4 Green D. Risk of future arterial cardiovascular events in patients with idiopathic venous thromboembolism. Hematology (Am Soc Hematol Educ Program) 2009;2009:259-266

5 Cohen AT, Gitt AK, Bauersachs R, et al. The management of acute venous thromboembolism in clinical practice. Results from the European PREFER in VTE Registry. Thromb Haemost 2017;117 (07):1326-1337

6 Klok FA, Hösel V, Clemens A, et al. Prediction of bleeding events in patients with venous thromboembolism on stable anticoagulation treatment. Eur Respir J 2016;48(05):1369-1376

7 Davidson BL, Verheijen S, Lensing AW, et al. Bleeding risk of patients with acute venous thromboembolism taking nonsteroidal anti-inflammatory drugs or aspirin. JAMA Intern Med 2014; 174(06):947-953

8 Alexander JH, Lopes RD, Thomas L, et al. Apixaban vs. warfarin with concomitant aspirin in patients with atrial fibrillation: insights from the ARISTOTLE trial. Eur Heart J 2014;35(04):224-232

9 Kearon C, Akl EA, Ornelas J, et al. Antithrombotic therapy for VTE disease: CHEST guideline and expert panel report. Chest 2016; 149(02):315-352

10 Douketis JD. Combination warfarin-ASA therapy: which patients should receive it, which patients should not, and why? Thromb Res 2011;127(06):513-517 